\title{
Encapsulation of human serum albumin in submicrometer magnetic poly(lactide-co-glycolide) particles as a model system for targeted drug delivery
}

Quazi T.H. Shubhra, ${ }^{1}$ Hana Macková, ${ }^{2}$ Daniel Horák, ${ }^{2 \star}$ Andrea Fodor-Kardos, ${ }^{1,3}$ Judit Tóth, ${ }^{1,3}$ János Gyenis, ${ }^{1}$ Tivadar Feczkó ${ }^{1,3}$

1 Research Institute of Chemical and Process Engineering, Doctoral School of Molecular and Nanotechnologies, Faculty of Information Technology, University of Pannonia, Egyetem u. 10, H-8200 Veszprém, Hungary

2 Institute of Macromolecular Chemistry, Academy of Sciences of the Czech Republic, Heyrovsky Sq. 2, 16206 Prague 6, Czech Republic; e-mail: horak@imc.cas.cz

${ }^{3}$ Institute of Materials and Environmental Chemistry, Research Center for Natural Sciences, Hungarian Academy of Sciences, Pusztaszeri u. 59-67, H-1025 Budapest, Hungary

(Received: 31 December, 2012; published: 11 July, 2013)

\begin{abstract}
Two types of iron oxide nanoparticles were synthesized by coprecipitation of $\mathrm{Fe}(\mathrm{II})$ and $\mathrm{Fe}(\mathrm{III})$ chlorides: water-dispersible $\mathrm{Y}-\mathrm{Fe}_{2} \mathrm{O}_{3}$ and organic solvent-dispersible oleic acid-coated $\mathrm{Fe}_{3} \mathrm{O}_{4}$ particles. The nanoparticles, together with human serum albumin (HSA) serving as a model for a protein-type drug, were then incorporated in poly(lactide-co-glycolide) (PLGA) particles using double emulsion solvent evaporation technique. Morphology, size and particle size distribution of the resulting particles was analyzed by electron microscopy and dynamic light scattering. Iron oxide and HSA encapsulating efficiency was determined by Prussian Blue staining and micro-BCA assay, respectively.
\end{abstract}

\section{Introduction}

Nanobiotechnologies are promising tools in biomedical and pharmaceutical sciences, in particular in controlled drug delivery systems and diagnostics. In the former, the nanoparticle-based systems offer three major advantages: (i) targeting of specific organs in the body, (ii) achieving an effective drug concentration in the target and (iii) minimizing undesirable side effects at non-target sites (Zhang et al. [1]). In the latter, the ability to recognize, label and image specific target cells is very important. Various nanoparticles, that have to be biocompatible and biodegradable, are designed for these purposes (De Jong et al. [2], Shao et al. [3]).

Poly(D,L-lactic-co-glycolide) (PLGA) is a biocompatible (non-toxic) and biodegradable material that is FDA approved and often used for preparation of nanoand microparticles (Kona et al. [4], Galeska et al. [5]). Moreover, it has excellent drug-loading capacity. It is a great advantage that drugs that are encapsulated inside the polymer nanoparticles or nanocapsules can be efficiently protected against enzymatic and hydrolytic degradation. Moreover, if the particles contain magnetic core, they can be manipulated by magnetic field or monitored by magnetic resonance imaging. For example, anionic magnetic nanoparticles have been used to adsorb and release cationic drugs for potential cancer immunotherapy (Mejías et al. [6]). 
Magnetic nanoparticles are often based on iron oxides, such as magnetite $\left(\mathrm{Fe}_{3} \mathrm{O}_{4}\right)$ or maghemite $\left(\mathrm{\gamma}-\mathrm{Fe}_{2} \mathrm{O}_{3}\right)$. Both of them are nontoxic and FDA-approved for clinical use. Although other metals (or its oxides), such as cobalt and nickel, are highly magnetic materials compared to iron oxides, they are toxic. While $\mathrm{Fe}_{3} \mathrm{O}_{4}$ has generally better magnetic properties than $\mathrm{y}-\mathrm{Fe}_{2} \mathrm{O}_{3}$, the latter is less susceptible to oxidation than the former. If oxidation of magnetic nanoparticles occurs inside the body, highly reactive hydroxyl radicals will be formed which can cause serious health risks.

Encapsulation of low- and high-molecular-weight molecules (drugs) by a polymer can be achieved by several methods such as micro/nanoemulsion (Lee at al. [7], Wang et al. [8], Urban et al. [9]), nanoprecipitation (Staunmesse at al. [10], Cheng at al. [11]), micelle formation (Kim at al. [12], Lu at al. [13], Talelli at al. [14]), emulsion polymerization (Ramírez et al. [15], Wormuth [16], Pollert et al. [17]) or solvent extraction/evaporation method (Feczkó at al. [18]). For instance, magnetic nanoparticle-embedded poly(lactide-co-glycolide) matrices were prepared as a dual drug-delivery and imaging system capable of encapsulating both hydrophilic (carboplatin) and hydrophobic (paclitaxel and rapamycin) drugs (Singh at al. [19]). Double emulsion combined with a solvent evaporation technique was often used for preparation of microspheres both in batch (Rosca et al. [20]) and microfluidic arrangement (Lee et al. [21]). Preparation of nanoparticles was also investigated but resulting particles typically had irregular shape (Fonte et al. [22], Zambaux et al. [23]). In the double emulsion solvent evaporation process, a primary emulsion (w/o) was formed by emulsifying the drug in an aqueous solution with a continuous organic phase containing a polymer and a solvent with low boiling point, usually dichloromethane or ethyl acetate. The primary emulsion was then mixed in an aqueous solution containing surfactant to produce a double emulsion (w/o/w) (Meng et al. [24], Jeffery et al. [25]). Microspheres were formed during solvent removal. The method was used for encapsulation of a wide range of proteins since it allowed hydrophilic proteins to be dissolved in aqueous phase. However, there was always a danger that activity of proteins could be changed by contact with the organic interface (Sah [26]). The double emulsion solvent evaporation technique was also examined to produce magnetic particles (Ngaboni Okassa et al. [27]). In this method, an aqueous suspension of $\mathrm{Fe}_{3} \mathrm{O}_{4}$ was emulsified in an organic solvent containing a preformed polymer. Aggregation of $\mathrm{Fe}_{3} \mathrm{O}_{4}$ particles made it difficult to prepare individual magnetic polymer particles (Gomez-Lopera et al. [28]). Moreover, the polymer shell was usually heterogeneous or the $\mathrm{Fe}_{3} \mathrm{O}_{4}$ was not completely covered by the polymer. Although there are many reports on preparation of PLGA micro- and nanoparticles for different drug depot systems (Jain [29], Péan et al. [30], Hans et al. [31], Yang et al. [32]), only few reports on drug-loaded magnetic PLGA particles were published (Akbarzadeh at al. [33], Zhou at al. [34], Andhariya at al. [35]).

Aim of this report was to prepare human serum albumin (HSA)-loaded magnetic PLGA particles in submicrometer size using double emulsion solvent evaporation method. HSA, the most abundant plasma protein in the human body, served as a model for a protein-type drug. Such magnetic PLGA particles with protein-type drug depots should combine the advantage of biodegradability of the carrier with its easy handling by a magnetic field. 


\section{Results and discussion}

\section{Iron oxide nanoparticles}

Iron oxides, such as magnetite $\left(\mathrm{Fe}_{3} \mathrm{O}_{4}\right)$ and maghemite $\left(\gamma-\mathrm{Fe}_{2} \mathrm{O}_{3}\right)$, have advantage that they are currently the only accepted nontoxic magnetic materials for biomedical applications. Many methods producing superparamagnetic iron oxide nanoparticles have been already described (Nymfeo et al. [41], Sun et al. [42]). In this report, precipitation approach in water has been selected since it provides magnetic nanoparticles from readily available chemicals in a single step. Two types of magnetic nanoparticles were prepared: those dispersible in water and in organic media.

First type of magnetic nanoparticles dispersible in water included the iron oxide that was synthesized at room temperature in air by coprecipitation in water of ferrous and ferric chloride with $\mathrm{NH}_{4} \mathrm{OH}$ by modification of previously reported method (Massart [37]). The mole ratio of $\mathrm{Fe}(\mathrm{II})$ to $\mathrm{Fe}(\mathrm{III})$ had to be close to $1 / 2$. On addition of $\mathrm{NH}_{4} \mathrm{OH}$, the initially clear yellow solution immediately turned black, indicating the precipitation of $\mathrm{Fe}_{3} \mathrm{O}_{4}$ nanoparticles. To ensure oxidation stability of the nanoparticles, $\mathrm{Fe}_{3} \mathrm{O}_{4}$ was oxidized with $\mathrm{NaClO}$ solution to $\mathrm{y}-\mathrm{Fe}_{2} \mathrm{O}_{3}$ that is more stable against oxidation than $\mathrm{Fe}_{3} \mathrm{O}_{4}$. To obtain a stable colloidal solution of magnetic nanoparticles (ferrofluid), repulsive interactions preventing aggregation were provided by citrate ions on the particle surface. Careful washing, which removed all low-molecular-weight products (salts), peptized the precipitate under the formation of colloid. Figure 1 a shows TEM image of dry $\mathrm{Y}^{-} \mathrm{Fe}_{2} \mathrm{O}_{3}$ nanoparticles, shape of which resembled to spheres. The average nanoparticle size, $11 \mathrm{~nm}$, with polydispersity index PDI $=1.20$, was determined by averaging the diameters of hundreds of particles. As expected, hydrodynamic size of the $\mathrm{y}-\mathrm{Fe}_{2} \mathrm{O}_{3}$ particles in water was much larger $\left(D_{\mathrm{h}}=105 \mathrm{~nm}\right.$; polydispersity $\mathrm{PI}=0.19$ ) due to the fact that the particle doublets, triplets and aggregates were measured in water. Moreover, while microscopic methods determined number-average size of dry particles, dynamic light scattering calculated $z$-average of particles in water which was very sensitive to large objects. Both PDI and $\mathrm{PI}$ values thus suggested that even the monodisperse nanoparticles were not obtained, the particle size distribution was not extremely broad.

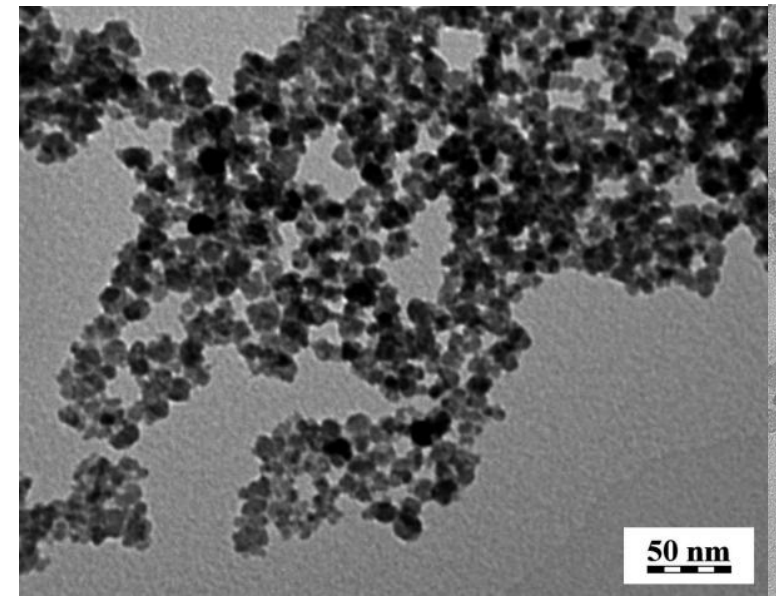

a

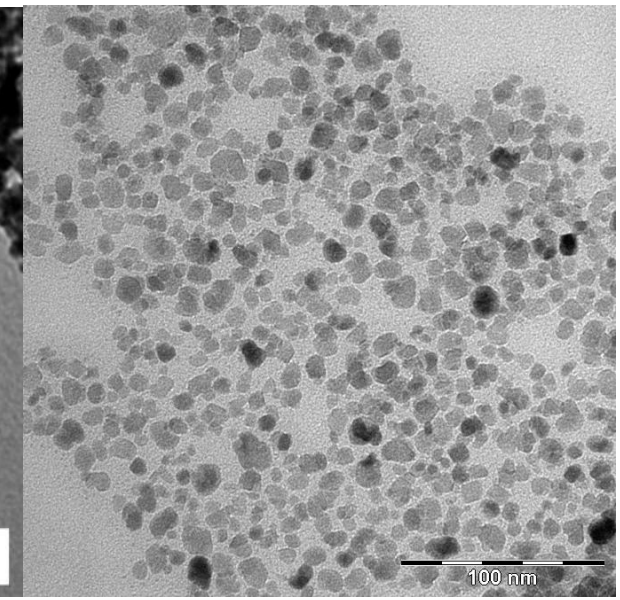

b

Fig. 1. TEM micrographs of (a) citrate-stabilized $\mathrm{y}-\mathrm{Fe}_{2} \mathrm{O}_{3}$ nanoparticles dried from water and (b) oleic acid-coated $\mathrm{Fe}_{3} \mathrm{O}_{4}$ nanoparticles dried from dichloromethane. 
Second type of magnetic nanoparticles involved a ferrofluid based on organic media. Here, ferrous and ferric salts were reduced by ammonia under nitrogen atmosphere to prevent oxidation of resulting $\mathrm{Fe}_{3} \mathrm{O}_{4}$. Oleic acid, that possesses carboxyl group readily adhering to the surface of an iron oxide nanoparticle, was at $90{ }^{\circ} \mathrm{C}$ used as a coating to ensure colloidal stability (preventing aggregation) of the particles in an organic medium (DCM). The stability was achieved by the long alkyl chains of oleic acids that float in the organic medium. In order to transfer primary $\mathrm{Fe}_{3} \mathrm{O}_{4}$ particles from aqueous to the DCM medium, they were first peptized yielding an asphalt-like paste from which water was easily removed. The paste, free of water, was then ultrasonically dispersed in DCM forming a colloid. The good dispersibility of oleic acid-coated $\mathrm{Fe}_{3} \mathrm{O}_{4}$ nanoparticles in nonpolar solvents was a result of their hydrophobization. Morphology, size and particle size distribution of the synthesized nanoparticles were again analyzed by TEM (Figure $1 \mathrm{~b}$ ). The particles did not have strictly regular spherical shape, their size was $10 \pm 5 \mathrm{~nm}$, i.e., they were not monodisperse but the particle size distribution was not too broad ( $P D I=1.29$ ). Hydrodynamic size of oleic acid-coated $\mathrm{Fe}_{3} \mathrm{O}_{4}$ was measured in DCM reaching $D_{\mathrm{h}}=$ $365 \mathrm{~nm}$ due to the particle aggregation; polydispersity was therefore rather high ( $\mathrm{PI}=$ 0.39).

\section{HSA-loaded magnetic PLGA particles}

The magnetic PLGA particles were prepared by the double emulsion solvent evaporation method in the presence of both HSA and iron oxide colloids. The method was chosen due to its simplicity and easy processing. It has other advantages like the particle size can be controlled by changing reaction parameters, purity of the particles is satisfactory and encapsulation efficiency high.

The first approach consisted in the addition of the inner aqueous phase containing $\mathrm{HSA}$ to the oleic acid-coated $\mathrm{Fe}_{3} \mathrm{O}_{4}$ in DCM containing PLGA to form w/o emulsion. The system was then emulsified in the outer aqueous phase with dissolved PVA to get $\mathrm{w} / \mathrm{o} / \mathrm{w}$ emulsion. Figure $2 \mathrm{a}, \mathrm{b}$ shows SEM and TEM micrographs of HSA-loaded magnetic PLGA particles containing 1 wt.\% oleic acid-coated $\mathrm{Fe}_{3} \mathrm{O}_{4}$ (relative to PLGA). The product consisted of majority of particles with $D_{n}=159 \mathrm{~nm}(\mathrm{PDI}=1.16)$ and a small family of large polydisperse particles $\left(D_{n}=356 \mathrm{~nm}\right.$ and PDI $\left.=1.76\right)$ which were obviously aggregates of small particles (Figure 2 a). The particle size was also measured by DLS in water according to which $D_{\mathrm{h}}=213 \mathrm{~nm}$ and $\mathrm{PI}=0.05$. The size distribution found by DLS was unimodal; the reason may be that the measured dispersion contained the emulsifier, which was removed by washing before the SEM analysis, where some aggregates were observed. In order to get a better contrast compared to SEM image and to confirm encapsulation of $\mathrm{Fe}_{3} \mathrm{O}_{4}$ in the polymer, HSA-loaded magnetic PLGA particles were viewed also by TEM (Figure 2 b). Figure $2 \mathrm{~b}$ shows that aggregates of oleic acid-coated $\mathrm{Fe}_{3} \mathrm{O}_{4}$ nanoparticles were dispersed inside a PLGA particle.

In the second method, the inner aqueous phase contained both water-based citratestabilized $\mathrm{y}-\mathrm{Fe}_{2} \mathrm{O}_{3}$ nanoparticles and $\mathrm{HSA}$. This phase was added to a solution of PLGA in DCM to prepare the first emulsion that was then mixed in aqueous PVA solution to get the double emulsion. The resulting HSA-loaded magnetic PLGA particles, although not strictly spherical, were smaller in size than those obtained by the first approach. Mean size was $85 \mathrm{~nm}$ and the particles had a tendency to aggregation in dry state as documented by PDI $=1.4$ (Figure $2 \mathrm{c}$ ). TEM image 
confirmed that a PLGA particle contained inhomogeneously dispersed $\gamma-\mathrm{Fe}_{2} \mathrm{O}_{3}$ nanoparticle aggregates (Figure $2 \mathrm{~d}$ ).

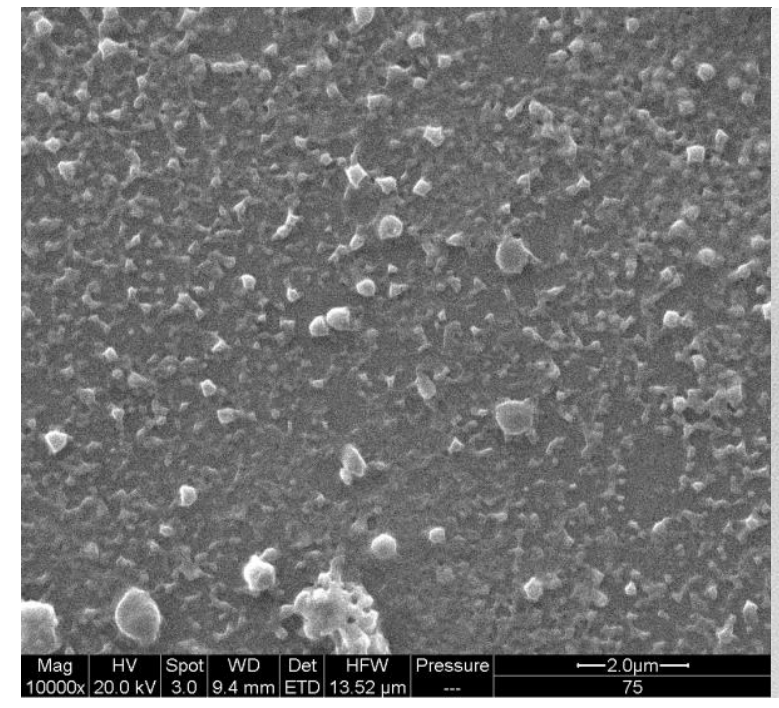

a

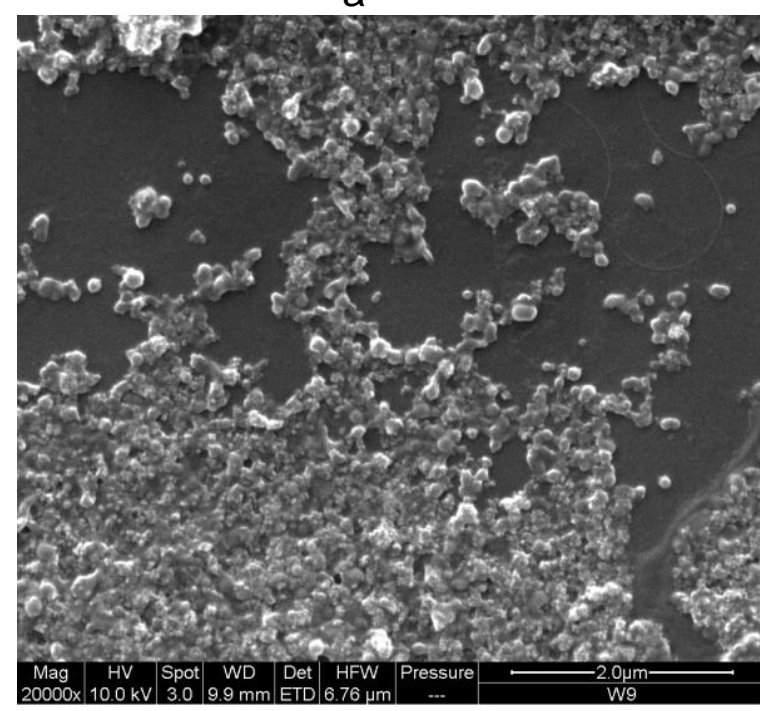

C

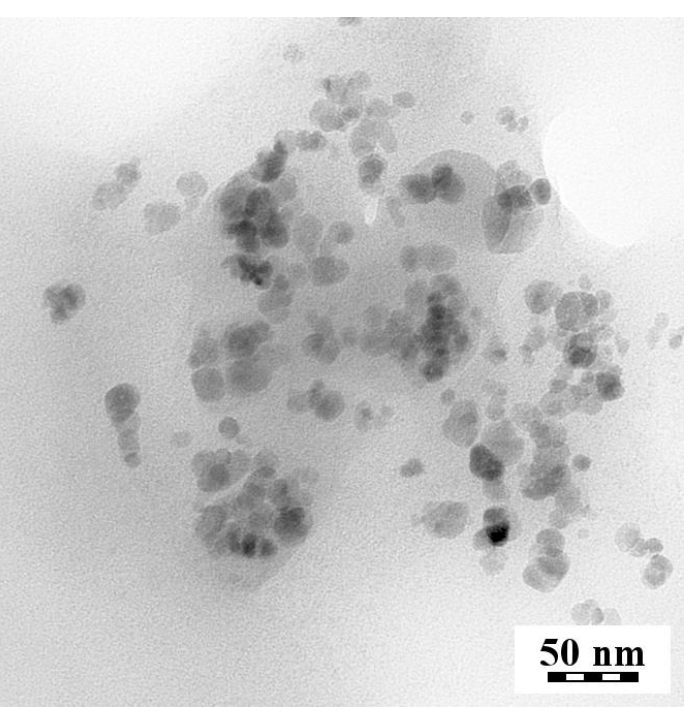

b

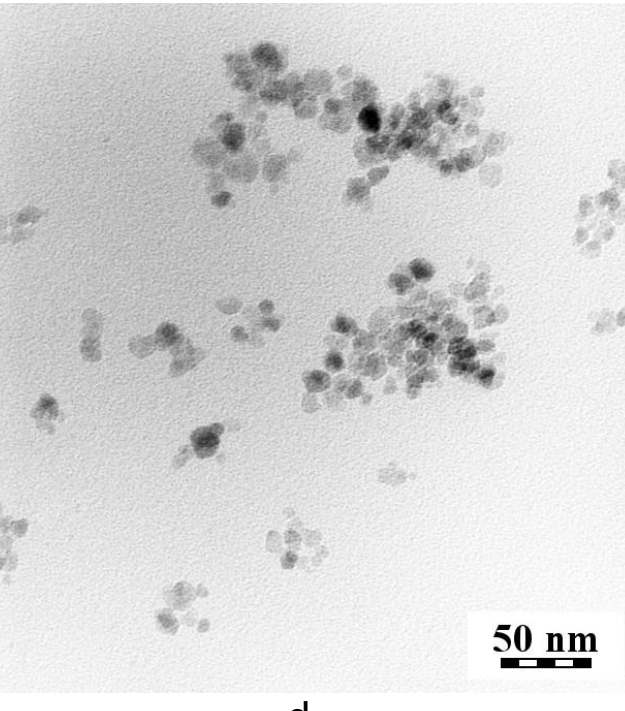

d

Fig. 2. SEM (a, c) and TEM (b, d) micrographs of HSA-loaded submicrometer magnetic PLGA particles. 1 wt.\% of $(a, b)$ oleic acid-coated $\mathrm{Fe}_{3} \mathrm{O}_{4}$ or $(\mathrm{c}, \mathrm{d})$ citratestabilized $\mathrm{y}-\mathrm{Fe}_{2} \mathrm{O}_{3}$ relative to PLGA.

In terms of HSA and iron oxide encapsulation efficiency, both methods of the iron oxide preparation were considered: (i) aqueous citrate-stabilized $y-\mathrm{Fe}_{2} \mathrm{O}_{3}$ colloid and (ii) oleic acid-coated $\mathrm{Fe}_{3} \mathrm{O}_{4}$ nanoparticles dispersed in organic medium. HSA encapsulation efficiency was sufficiently high for both types of magnetic PLGA particles prepared from two different iron oxide types, that is, it was found to be $89.2 \%$ for (i) and $87.6 \%$ for (ii). The encapsulation efficiencies of iron oxide were also high, i.e., $92.0 \%$ for (i) and $99.6 \%$ for (ii), respectively.

\section{Conclusions}

In this report, two kinds of iron oxide nanoparticles were synthesized: oleic acidcoated $\mathrm{Fe}_{3} \mathrm{O}_{4}$ in DCM and citrate-stabilized $\mathrm{y}-\mathrm{Fe}_{2} \mathrm{O}_{3}$ in water. The oleic acid adsorbed 
on the surfaces of $\mathrm{Fe}_{3} \mathrm{O}_{4}$ particles because of the complexation of carboxyl groups with iron ions. The long alkyls of oleic acid not only stabilized the $\mathrm{Fe}_{3} \mathrm{O}_{4}$ nanoparticles, preventing their coagulation, but also enhanced the affinity of the $\mathrm{Fe}_{3} \mathrm{O}_{4}$ nanoparticles to the hydrophobic PLGA in the subsequent double emulsion solvent evaporation process. On the other hand, $\mathrm{Y}-\mathrm{Fe}_{2} \mathrm{O}_{3}$ nanoparticles were electrostatically stabilized in water due to the citrate present on the particle surface.

In the next step, both types of iron oxide nanoparticles together with a model protein drug (HSA) were encapsulated in PLGA particles using the double emulsion solvent evaporation method. While aqueous $\mathrm{y}-\mathrm{Fe}_{2} \mathrm{O}_{3}$ colloid was added in the primary water phase of the system, oleic acid-coated $\mathrm{Fe}_{3} \mathrm{O}_{4}$ was present in the oil (DCM) phase. The resulting HSA-loaded magnetic PLGA particles had submicrometer size and they were relatively stable in aqueous media. Avoidance of particle aggregation is important in terms of designing injection drug formulations and allowing sterilization by ultra-filtration. Moreover, such particles could provide a dual drug-delivery and imaging system using magnetic force to target the drug-loaded vehicles to a specific organ and at the same time to monitor their migration by magnetic resonance imaging.

In conclusion, both aqueous and organic iron oxide colloids can be used for preparation of HSA-loaded submicrometer-sized magnetic PLGA particles. Magnetic PLGA particles might be thus promising for targeted drug delivery.

\section{Experimental}

\section{Materials}

$\mathrm{FeCl}_{2} \cdot 4 \mathrm{H}_{2} \mathrm{O}$ and $\mathrm{FeCl}_{3} \cdot 6 \mathrm{H}_{2} \mathrm{O}$ were purchased from Fluka (Buchs, Switzerland), sodium hypochlorite solution ( $\mathrm{NaClO}$ ) from Bochemie (Bohumín, Czech Republic), and sodium citrate dihydrate from Lachema (Brno, Czech Republic). Poly $(D, L-$ lactide-co-glycolide) (50:50; Resomer ${ }^{\circledR}$ RG $502 \mathrm{H}$ ) was from Boehringer (Ingelheim, Germany), poly(vinyl alcohol) (PVA; $M_{w}=30,000-70,000 ; 89-90 \%$ hydrolyzed) from Sigma-Aldrich (St. Luis, USA), human serum albumin (HSA) was from Trigon Biotechnological (Budapest, Hungary) and dichloromethane (DCM) was from Spektrum-3D (Hungary). Micro-BCA protein assay reagents were purchased from Pierce (Bonn, Germany). Oleic acid and other reagents were from LachNer (Neratovice, Czech Republic). Ultrapure Q-water ultrafiltered on a Milli-Q Gradient A10 system (Millipore, Molsheim, France) was used throughout the work.

\section{Synthesis of superparamagnetic citrate-stabilized $y-\mathrm{Fe}_{2} \mathrm{O}_{3}$ nanoparticles dispersible in aqueous media}

Earlier published procedures (Macková et al. [36], Massart [37]) were modified. First, magnetite $\left(\mathrm{Fe}_{3} \mathrm{O}_{4}\right)$ nanoparticles were prepared by coprecipitation from a mixture of $\mathrm{FeCl}_{2}$ and $\mathrm{FeCl}_{3}$ (molar ratio 1:2) upon addition of $\mathrm{NH}_{4} \mathrm{OH}$. Briefly, $0.5 \mathrm{M} \mathrm{NH}_{4} \mathrm{OH}(80$ $\mathrm{ml}$ ) was for 5 min added under sonication (W 385 Sonicator; Cole-Palmer Instruments, USA; output $40 \%$ ) to $0.2 \mathrm{M} \mathrm{FeCl}_{3}$ aqueous solution ( $\left.80 \mathrm{ml}\right)$, followed by the addition of $0.2 \mathrm{M} \mathrm{FeCl}_{2}$ aqueous solution $(40 \mathrm{ml})$. The mixture was poured into $0.5 \mathrm{M} \mathrm{NH}_{4} \mathrm{OH}(240 \mathrm{ml})$ under vigorous stirring $(2,000 \mathrm{rpm})$ with an anchor-type stirrer resulting in the precipitate, which was then left standing for $30 \mathrm{~min}$ and washed with Q-water (5 times $20 \mathrm{ml}$ ) until peptization was achieved. 5 wt.\% $\mathrm{NaClO}$ aqueous solution $(10 \mathrm{ml})$ was added under sonication followed by the addition of $0.1 \mathrm{M}$ sodium 
citrate solution $(13 \mathrm{ml})$ during $5 \mathrm{~min}$. The resulting citrate-stabilized $\mathrm{y}-\mathrm{Fe}_{2} \mathrm{O}_{3}$ nanoparticles were washed as above and sonicated for 5 min to achieve a concentration of $5 \mathrm{wt} . \%$.

Synthesis of superparamagnetic oleic acid-coated $\mathrm{Fe}_{3} \mathrm{O}_{4}$ nanoparticles dispersible in organic media

Neat superparamagnetic nanoparticles were prepared by coprecipitation of $\mathrm{FeCl}_{2}$ and $\mathrm{FeCl}_{3}$ in aqueous ammonia solution by modification of an earlier published method (Horák et al. [38]). Briefly, $\mathrm{FeCl}_{3} \cdot 6 \mathrm{H}_{2} \mathrm{O}(24.32 \mathrm{~g})$ and $\mathrm{FeCl}_{2} \cdot 4 \mathrm{H}_{2} \mathrm{O}(11.92 \mathrm{~g}$; molar ratio 2:1) were stirred at $400 \mathrm{rpm}$ in Q-water $(50 \mathrm{ml})$ under nitrogen atmosphere. To this solution, $28 \% \mathrm{NH}_{4} \mathrm{OH}$ solution ( $50 \mathrm{ml} ; 50 \%$ excess) was added over a period of 20-30 min. To coat the nanoparticles, oleic acid $(5 \mathrm{ml})$ was added to the reaction mixture at $90{ }^{\circ} \mathrm{C}$ and the reaction proceeded for $5 \mathrm{~h}$ until the $\mathrm{NH}_{3}$ odor disappeared. After cooling to room temperature, the $\mathrm{Fe}_{3} \mathrm{O}_{4}$ nanoparticles were washed with Qwater for 4 days (three times $200 \mathrm{ml}$ a day) using separation by a magnet and decantation; they were then dried at $80^{\circ} \mathrm{C}$ and $13 \mathrm{~Pa}$ to yield about $16 \mathrm{~g}$ of product. Finally, the $\mathrm{Fe}_{3} \mathrm{O}_{4}$ particles were under sonication resuspended in dichloromethane (DCM) to a concentration of $5.7 \mathrm{wt} . \%$.

\section{Encapsulation of citrate-stabilized $y-\mathrm{Fe}_{2} \mathrm{O}_{3}$ or oleic acid-coated $\mathrm{Fe}_{3} \mathrm{O}_{4}$ nanoparticles by PLGA}

Particles containing HSA and oleic acid-coated $\mathrm{Fe}_{3} \mathrm{O}_{4}$ (or citrate-stabilized $\mathrm{y}-\mathrm{Fe}_{2} \mathrm{O}_{3}$ ) were formulated by a double emulsion solvent evaporation technique.

Briefly, aqueous solution $(0.5 \mathrm{ml})$ of $\mathrm{HSA}(3.7 \mathrm{mg})$ was added to oil phase (DCM; 5 $\mathrm{ml}$ ) containing PLGA $(200 \mathrm{mg})$ and oleic acid-coated $\mathrm{Fe}_{3} \mathrm{O}_{4}(2 \mathrm{mg})$ dispersed in DCM. This two-phase system was emulsified using a model W-220 probe sonicator (Heat Systems-Ultrasonics) for $1 \mathrm{~min}$ to get a water-in-oil (w/o) emulsion. The resulting emulsion was further homogenized in $2 \mathrm{wt}$ \% PVA aqueous solution (20 ml) for $2 \mathrm{~min}$ in an ice bath to obtain w/o/w emulsion. The DCM was evaporated from $\mathrm{w} / \mathrm{o} / \mathrm{w}$ emulsion using magnetic stirrer $(800 \mathrm{rpm})$ for $2 \mathrm{~h}$. The resulting PLGA particles were separated by centrifugation.

Optionally, aqueous phase $(0.5 \mathrm{ml})$ containing HSA $(3.7 \mathrm{mg})$ and citrate-stabilized $\mathrm{y}$ $\mathrm{Fe}_{2} \mathrm{O}_{3}(2 \mathrm{mg})$ was added to DCM (5 ml) containing PLGA (200 mg) and the system was treated in the same way as described above.

\section{Characterization}

Nanoparticle size $\left(D_{\mathrm{n}}\right)$, particle size distribution (polydispersity index $\mathrm{PDI}=D_{\mathrm{w}} / D_{\mathrm{n}}$, where $D_{\mathrm{w}}$ and $D_{\mathrm{n}}$ are weight- and number-average particle size, respectively) and morphology were determined using a Quanta S200 scanning electron microscope (SEM; FEI; Brno, Czech Republic) and a Tecnai Spirit G2 transmission electron microscope (FEl). Hydrodynamic diameter $\left(D_{h}\right)$ was measured by dynamic light scattering (DLS) using a Zeta-Sizer Nano ZS (Malvern Instruments; Malvern, UK). DLS characterizes particle size distribution by polydipersity PI typically in the range $0-0.3$, where 0 represents monodisperse particles and 0.3 their highly polydisperse counterparts (Koppel [39]).

Encapsulation efficiency of HSA was determined by micro-BCA assay using a Pharmacia LKB Biochrom 4060 UV-VIS spectrophotometer (Cambridge, UK). In micro-BCA assay, peptide bonds of protein reduced cupric $\left(\mathrm{Cu}^{2+}\right)$ to cuprous $\left(\mathrm{Cu}^{+}\right)$ 
ions and two molecules of bicinchonic acid chelated with each $\mathrm{Cu}^{+}$ion forming a purple-colored product that strongly absorbed light at $562 \mathrm{~nm}$. Content of nonencapsulated protein was determined in the supernatant using UV-VIS spectroscopy and amount of encapsulated HSA calculated.

Encapsulation efficiency of iron oxide in the sumicrometer-sized PLGA particles was determined after separation of non-encapsulated iron oxide from the particles. At first, suspension of magnetic PLGA particles in water was centrifuged at 30,000 rpm for 30 min using a Beckman Optima Max-E ultracentrifuge (Brea, USA) to remove PVA solution partly stabilizing the non-encapsulated iron oxide. The magnetic PLGA particles were then resuspended in distilled water, whilst the aggregated iron oxide nanoparticles remained in the precipitate since they were not stabilized anymore. After removal of the supernatant, the iron oxide content was determined in the precipitate by a colorimetric method using Prussian Blue staining (Astete et al. [40]). The iron oxide was dissolved by $6 \mathrm{M} \mathrm{HCl}$, the resulting $\mathrm{Fe}^{3+}$ solution was diluted with $1 \% \mathrm{HCl}$ and reacted with equal amount of $1 \%$ potassium ferrocyanide solution producing a deep blue colour. The absorbance was measured after 15 min by a UVVIS spectrophotometer at $700 \mathrm{~nm}$. Calibration was done with a stock solution of iron(III) oxide powder, $99.998 \%$ of purity.

\section{Acknowledgements}

Financial support of the European Commission (DiaTools project No. 259796) is gratefully acknowledged. The authors are also thankful to the bilateral academic exchange program of Hungarian Academy of Sciences and Academy of Sciences of the Czech Republic and project KAN401220801.

\section{References}

[1] Zhang J.; Lan C.Q.; Post M.; Simard B.; Deslandes Y.; Hsieh T.H. Cancer Genomics Proteomics 2006, 3, 147.

[2] De Jong W.H.; Borm P.J.A. Int. J. Nanomedicine 2008, 3, 133.

[3] Shao H.; Yoon T.J.; Liong M.; Weissleder R.; Lee H. Beilstein J. Nanotechnol. 2010, 1, 142.

[4] Kona S.; Dong J.F.; Liu Y.; Tan J.; Nguyen K.T. Int. J. Pharm. 2012, 423, 516.

[5] Galeska I.; Kim T.K.; Patil S.D.; Bhardwaj U.; Chatttopadhyay D.; Papadimitrakopoulos F.; Burgess D.J. AAPS J. 2005, 7, E231.

[6] Mejías R.; Costo R.; Roca A.G.; Arias C.F.; Veintemillas-Verdaguer S.; GonzálezCarreño T.; Morales M.D.; Serna C.J.; Mañes S.; Barber D.F. J. Controlled Release 2008, 130, 168.

[7] Lee S.J.; Jeong J.R.; Shin S.C.; Kim J.C.; Chang Y.H.; Lee K.H.; Kim J.D. Colloids Surf. A 2005, 255, 19.

[8] Wang Y.; Ng Y.W.; Chen Y.; Shuter B.; Yi J.; Ding J.; Wang S.C.; Feng S.S. Adv. Funct. Mater. 2008, 18, 308.

[9] Urban M.; Musyanovych A.; Landfester K. Macromol. Chem. Phys. 2009, 210, 961.

[10] Staunmesse S.; Orechioni A.M.; Nakache E.; Puisieux F.; Fessi H. Colloid Polym. Sci. 1995, 273, 505.

[11] Cheng J.; Teply B.A.; Sherifi I.; Sung J.; Luther G.; Gu F.X.; Levy-Nissenbaum E.; Radovic-Moreno A.F.; Langer R.; Farokhzad O.C. Biomaterials 2007, 28, 869.

[12] Kim B.S.; Qiu J.M.; Wang J.P.; Taton T.A. Nano Lett. 2005, 5, 1987. 
[13] Lu J.; Ma S.; Sun J.; Xia C.; Liu C.; Wang Z.; Zhao X.; Gao F.; Gong Q.; Song B.; Shuai X.; Ai H.; Gu Z. Biomaterials 2009, 30, 2919.

[14] Talelli M.; Rijcken C.J.F.; Lammers T.; Seevinck P.R.; Storm G.; van Nostrum C.F.; Hennink W.E. Langmuir 2009, 25, 2060.

[15] Ramírez L.P.; Landfester K. Macromol. Chem. Phys. 2003, 204, 22.

[16] Wormuth K. J. Colloid Interface Sci. 2001, 241, 366.

[17] Pollert E.; Knižek K.; Maryško M.; Závěta K.; Lančok A.; Boháček J.; Horák D.; Babič M. J. Magn. Magn. Mater. 2006, 306, 241.

[18] Feczkó T.; Tóth J.; Gyenis J. Colloids Surf. A 2008, 319, 188.

[19] Singh A.; Dilnawaz F.; Mewar S.; Sharma U.; Jagannathan N.R.; Kumar Sahoo S. ACS App. Mater. Interfaces 2011, 3, 842.

[20] Rosca I.D.; Watari F.; Uo M. J. Controlled Release 2004, 99, 271.

[21] Lee M.H.; Hribar K.C.; Brugarolas T.; Kamat N.P.; Burdick J.A.; Lee, D. Adv. Funct. Mater. 2012, 22, 131.

[22] Fonte P.; Nogueira T.; Gehm C.; Ferreira D. Drug Deliv. Transl. Res. 2011, 1, 299.

[23] Zambaux M.F.; Bonneaux F.; Gref R.; Maincent P; Dellacherie E.; Alonso M.J.; Labrude P.; Vigneron C. J. Controlled Release 1998, 50, 31.

[24] Meng F.T.; Ma G.H.; Qiu W.; Su Z.G. J. Controlled Release 2003, 91, 407.

[25] Jeffery H.; Davis S.S.; O'Hagan D.T. Pharm. Res. 1993, 10, 362.

[26] Sah H. J. Controlled Release 1999, 58, 143.

[27] Ngaboni Okassa L.; Marchais H.; Douziech-Eyrolles L.; Cohen-Jonathan S.; Soucé M.; Dubois P.; Chourpa I. Int. J. Pharm. 2005, 302, 187.

[28] Gomez-Lopera S.A.; Plaza R.C.; Delgado A.V.J. Colloid Interface Sci. 2001, 240, 40.

[29] Jain R.A. Biomaterials 2000, 21, 2475.

[30] Péan J.M.; Boury F.; Venier-Julienne M.C.; Menei P. Pharm. Res. 1999, 16, 1294.

[31] Hans M.L.; Lowman A.M. Curr. Opin. Solid State Mater. Sci. 2002, 6, 319.

[32] Yang Y.Y.; Chung T.S.; Ng N.P. Biomaterials 2001, 22, 231.

[33] Akbarzadeh A.; Mikaeili H.; Zarghami N.; Mohammad R.; Barkhordari A.; Davaran S. Int. J. Nanomed. 2012, 7, 511.

[34] Zhou S.B.; Sun J.; Sun L.; Dai Y.Q.; Liu L.P.; Li X.H.; Wan J.X.; Weng J.; Jia W.X.; Zhang Z.R. J. Biomed. Mater. Res., Part B 2008, 87B 189.

[35] Andhariya N.; Chudasama B.; Mehta R.V; Upadhyay R.V. J. Nanopart. Res. 2011, 13, 1677.

[36] Macková H.; Králová D.; Horák D. J. Polym. Sci., Part A: Polym. Chem. Ed. 2007, 45,5884 .

[37] Massart R. IEEE Trans. Magn. 1981, 17, 1247.

[38] Horák D.; Semenyuk N.; Lednický F. J. Polym. Sci., Part A: Polym. Chem. Ed. 2003, 41, 1848.

[39] Koppel D.E. J. Chem. Phys. 1972, 57, 4814.

[40] Astete C.E.; Kumar C.S.S.R.; Sabliov C.M. Colloid Surface A 2007, 299, 209.

[41] Nymfeo M.; Saxena S.; Tankhiwale R.; Bajpai M.; Mohan Y.M.; Bajpai S.K. J. Nanosci. Nanotechnol. 2008, 8, 3247.

[42] Sun C.; Lee J.S.; Zhang M. Adv. Drug Deliv. Rev. 2008, 60, 1252. 